\title{
Chondromyxoid Fibroma of Calcaneum - A Rare Case Report with Review of Literature
}

\author{
Amit Lakmani ${ }^{1}$, Ena Sharma ${ }^{2}$, Kevin Khatri ${ }^{3}$, Aman Hooda ${ }^{4}$ \\ ${ }^{1,4}$ Department of Orthopaedics, Dr. B. R. Ambedkar State Institute of Medical Sciences, Mohali, \\ Punjab, India. ${ }^{2}$ Department of Periodontics, Maharishi Markandeshwar College of Dental Sciences, \\ and Research, Mullana, Haryana, India. ${ }^{3}$ Department of Orthopaedics, All India Institute of Medical \\ Sciences, Bathinda Punjab, India.
}

\section{INTRODUCTION}

Chondromyxoid fibroma (CMF) is a slow-growing benign tumour seen in the metaphysis of a long bone. World health organization (WHO) Classification of Bone and Soft Tissue Tumours (2002) defines CMF as "benign tumour characterized by lobules of spindle or stellate-shaped cells with abundant myxoid or chondroid intercellular material. ${ }^{1}$ Jaffe and Lichtenstein were the first to describe this tumour in 1943.2 They differentiated CMF as a benign lesion from chondrosarcoma which is a much more common malignant tumour.

Chondromyxoid fibroma is a potentially aggressive tumour with a cartilage-like matrix. It accounts for approximately $1 \%$ of all bone tumors. ${ }^{3} \mathrm{CMF}$ is found in older children and young adults. This type of tumour normally affects people between the age of 10 to 30 years. ${ }^{3,4,5}$ It is associated with high local recurrence and with less than $2 \%$ of malignant transformation ${ }^{5}$. While the cells of the CMF tumour do not undergo metastasis, but they can invade nearby tissues. It is painful and causes other symptoms like swelling, stiffness, tenderness, and abnormal growth under the skin. The most common site of this lesion is the tibia and other affected sites are the flat and facial bones, and sparsely in bones of the feet and hand.6,7,8,9 Its occurrence in calcaneum is rarely seen. ${ }^{9}$ So here we report a case of a female patient, presented with cystic swelling and pain in the left foot, which was diagnosed as CMF in excision biopsy.

\section{PRESENTATION OF CASE}

A 16-year-old young active female was presented in the outpatient department of MMMCH with the chief complaint of painful swelling in the left lateral aspect of the foot for 4 months. There was no history of trauma, fever, TB (tuberculosis) or any previous surgery. The onset of swelling was gradual and progressive from 4 months with aggravation in pain on walking. On palpation, there was a firm swelling on the lateral aspect of the foot with a distinct margin and normal overlying skin [figure 1]. It was tender and approximately $3 \times 4 \mathrm{~cm}$ in size. The range of motion was normal at the ankle and subtalar joint. There was no associated neurovascular deficit.

A radiographic examination showed a radiolucent, eccentric lesion with a sclerotic margin in the calcaneum. There were septations with no sign of new periosteal bone formation [figure 2]. Computerised tomography (CT) scan of calcaneum showed a large lytic lesion with a distinct border and intact overlying cortex [figure 3]. Fine needle aspiration cytology (FNAC) was conducted as a primary investigation which confirmed the benign nature of the lesion and suggested chondroblastoma as the preeminent.
Corresponding Author:

Dr. Ena Sharma,

Department of Periodontics,

Maharishi Markandeshwar

College of Dental sciences and

Hospital (Deemed to Be University),

Mullana Ambala, Haryana, India.

E-mail: dr.sharma_ena@yahoo.co.in

DOI: $10.14260 / j e m d s / 2021 / 303$

How to Cite This Article:

Lakmani A, Sharma E. Khatri $K$, et al. Chondromyxoid fibroma of calcaneum - a rare case report with review of literature. J Evolution Med Dent Sci 2021;10(19):14441447, DOI: 10.14260/jemds/2021/303

Submission 08-12-2020,

Peer Review 23-02-2021,

Acceptance 01-03-2021,

Published 10-05-2021.

Copyright (c) 2021 Amit Lakmani et al. This is an open access article distributed under Creative Commons Attribution License [Attribution 4.0 International (CC BY 4.0)] 


\section{DISCUSSION OF MANAGEMENT}

The patient was planned for intralesional curettage after relevant investigations. The lesion was extended and curetted through a lateral approach and filled with a bone graft from the iliac crest [figure 4]. Postoperatively, the patient was given a plaster of Paris (POP) slab for 2 weeks. After stitch removal, we applied below-knee plaster cast partial weight-bearing for a further six weeks. Full weight-bearing was started after ten weeks. The graft got consolidated at three months postoperatively. With the one-year follow-up, there was no sign of recurrence.

\section{PATHOLOGICAL DISCUSSION}

The histological examination revealed fibro collagenous stroma and myxochondroid islands with stellate-shaped cells. The myxoid material was separated by fibrous septa along with peripheral giant cells. This confirmed the diagnosis of CMF [figure 5,6]

\section{DIFFERENTIAL DIAGNOSIS}

Chondroblastoma, Giant cell tumour, Chondrosarcoma

\section{DISCUSSION}

Soft tissue and bone tumours of the foot are not rare, but their diagnosis is usually delayed due to common findings with pseudotumours lesion. Regarding anatomical localization, the hindfoot is affected most often. The most prevalent benign bone tumour in the foot includes simple bone cysts, enchondroma, and osteochondroma and the most common malignant bone tumour is chondrosarcoma.

The occurrence of CMF in the foot is very uncommon. This tumour is seen in males more frequently, it is benign and there have been no reports of metastases. ${ }^{10}$ Chondromyxoid fibroma is considerably puzzling in diagnosis due to similar pathologic entities with more aggressive tumours such as chondrosarcoma. ${ }^{11}$ For establishing an accurate diagnosis of the tumour, a thorough clinical, radiological, and histopathological examination is very essential. In accordance with various literature, CMF presents as an oval, osteolytic, expansile lobulated lesion or. It has précised margins and a sclerotic rim as seen in an x-ray. In long bones, the metaphyseal region often gets affected and eccentric. If epiphysis is involved, there is a high probability of chondroblastoma and giant cell tumours. A characteristic appearance of CMF is nearly a hemispherical "bite" without periosteal reaction. ${ }^{12,13}$ Cortical changes and breakthrough to the destruction of the cortex are best evaluated on CT. Internal bony trabeculation is commonly seen on CT and was prominent on $\mathrm{x}$-ray, which may be due to corrugation and scalloping at the edge in our case. Internal calcification is rare, seen in only $2-13 \%$ of lesions. ${ }^{14}$ This patient has an osteolytic lesion with an intact cortical margin with subtle internal calcification on CT. But the diagnosis of CMF on x-ray and CT scan is uncertain.

Histopathology is a gold standard investigation in the diagnosis of CMF. The typical histological features of CMF are hypocellular centers and hypercellular boundaries. Osteoclast-like giant cells are at the lobular peripheries, lobular pattern with stellate-shaped cells in a chondroid or myxoid framework in the center. ${ }^{15,16}$ Dahlin stressed that giant cells at the boundaries of the chondroid lobules with plump hyperchromatic nuclei besides nuclear atypism are indicative of CMF. ${ }^{17}$ Similar characteristics have established diagnosis in this report. Though FNAC suggested chondroblastoma as the primary diagnosis, histopathology after excision of biopsy confirmed the diagnosis and helped us to provide correct treatment and restricted unnecessary interventions.

Treatment options are intralesional curettage with bone grafting, additional cementation, and amputation. ${ }^{6}$ Complete removal of the chondromyxoid fibroma by resection with tumour bed is very important to prevent the high rate of recurrence. The efficacy of such complete resection has been documented by Schajowicz and Gallard ${ }^{18}$ and advisable by observing excellent results with treatment of recurrent tumours. Radiation treatment for this tumour is contraindicated, with the possible peculiarity of surgically inaccessible tumours. Serious side effects to radiation therapy were seen in two cases in a series by Rahimi A. ${ }^{19}$

So, in conclusion, CMF is a rare and benign tumor of metaphysis regions of long bones with an unusual presentation in feet. Although $\mathrm{x}$-ray is important in diagnosis, a CT scan is more relevant to see cortical breach. However, histopathology remains a gold standard for diagnosis and to differentiate from other tumors. Intralesional curettage is the treatment of choice for both therapeutic and diagnostic. This is an uncommon case report of CMF calcaneum in the Indian population and no other case is mentioned in literature to date after 2012 .

\section{FINAL DIAGNOSIS}

Chondromyxoid fibroma

Financial or other competing interests: None.

Disclosure forms provided by the authors are available with the full text of this article at jemds.com. 


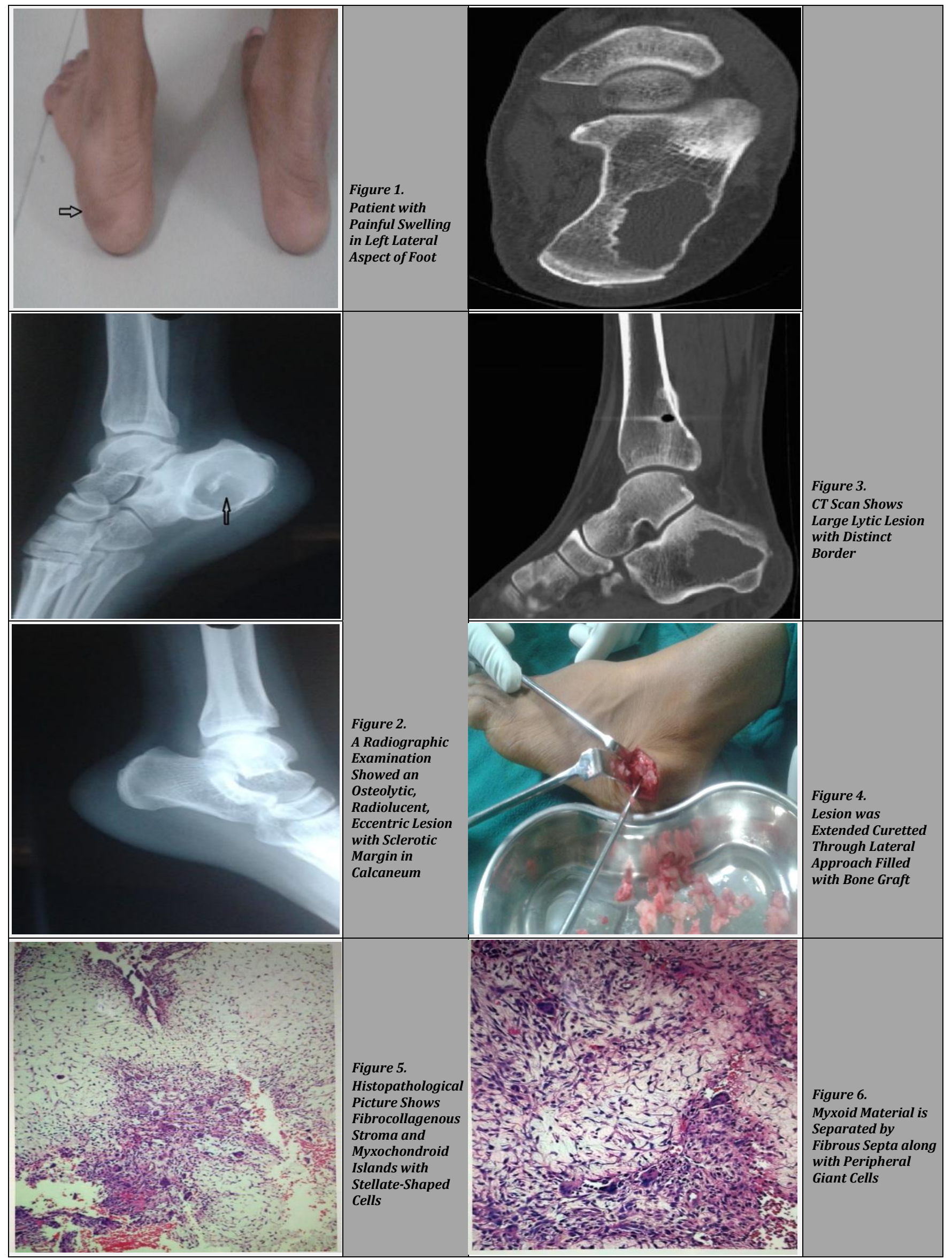




\section{REFERENCES}

[1] Fletcher CDM, Unni KK, Mertens F. World Health Organization Classification of Tumours. Pathology and genetics of tumours of soft tissue and bone. Lyon, France: IARC Press 2002.

[2] Jaffe HL, Lichtenstein L. Chondromyxoid fibroma of bone: a distinctive benign tumour likely to be mistaken for chondrosarcoma. Arch Pathol (Chic) 1948;45(4):541-51.

[3] Campanacci M, Bertoni F, Bacchini P. Bone and soft tissue tumours. New York: Springer-Verlag 1990.

[4] Unni KK. Chondromyxoid fibroma. In: Dahlin's Bone Tumours. General aspects and data on 11,087 cases. $5^{\text {th }}$ edn. Philadelphia: Lippincott Williams \& Wilkins 1996: p. 59-69.

[5] Wu CT, Inwards CY, O'Laughlin S, et al. Chondromyxoid fibroma of bone: a clinicopathologic review of 278 cases. Hum Pathol 1998;29(5):438-46.

[6] Bhamra JS, Al-Khateeb H, Dhinsa BS, et al. Chondromyxoid fibroma management: a single institution experience of 22 cases. World J Surg Oncol 2014;12:283.

[7] Anderson WJ, Bowers WH. Chondromyxoid fibroma of the proximal phalanx. A tumour that may be confused with chondrosarcoma. J Hand Surg Br 1986;11(1):144-6.

[8] Merine D, Fishman EK, Rosengard A, et al. Chondromyxoid fibroma of the fibula. J Pediatr Orthop 1989;9(4):468-71.

[9] Desai SS, Jambhekar NA, Samanthray S, et al. Chondromyxoid fibromas: a study of 10 cases. J Surg Oncol 2005;89(1):28-31.
[10] Dürr HR, Lienemann A, Nerlich A, et al. Chondromyxoid fibroma of bone. Arch Orthop Trauma Surg 2000;120(12):42-7.

[11] Lersundi A, Mankin HJ, Mourikis A, et al. Chondromyxoid fibroma: a rarely encountered and puzzling tumour. Clin Orthop Relat Res 2005;439:171-5.

[12] Wilson AJ, Kyriakos M, Ackerman LV. Chondromyxoid fibroma: radiographic appearance in 38 cases and in a review of the literature. Radiology 1991;179(2):513-8.

[13] Beggs IG, Stoker DJ. Chondromyxoid fibroma of bone. Clin Radiol 1982;33(6):671-97.

[14] Douis H, Saifuddin A. The imaging of cartilaginous bone tumours. I. Benign lesions. Skeletal Radiol 2012;41(10):1195-212.

[15] Crocker M, Corns R, Bodi I, et al. Chondromyxoid fibroma of the skull base invading the occipitocervical junction: report of a unique case and discussion. Skull Base 2010;20(2):101-4.

[16] Giambelli G, Mincione A. Chondromyxoid fibroma of the calcaneus. Minerva Ortop 1964;15:20-3.

[17] Damle RP, Suryawanshi KH, Dravid NV, et al. Chondromyxoid fibroma of bone. Journal of Case Reports 2013;3(2):228-31.

[18] Schajowicz F, Gallardo H. Chondromyxoid fibroma (fibromyxoid chondroma) of bone: a clinic-pathological study of thirty-two cases. J Bone Joint Surg Br 1971;53(2):198-216.

[19] Rahimi A, Beabout JW, Ivins JC, et al. Chondromyxoid fibroma: a clinicopathologic study of 76 cases. Cancer 1972;30(3):726-36. 